\title{
Identification of Polypropylene Glycols and Polyethylene Glycol Carboxylates in Flowback and Produced Water from Hydraulic Fracturing
}

\author{
by \\ E. Michael Thurman*, Imma Ferrer, James Rosenblum, Karl Linden, and Joseph N. Ryan \\ Department of Civil, Environmental, and Architectural Engineering, \\ University of Colorado, Boulder, CO, USA 80503
}

\begin{abstract}
The purpose of the study was to separate and identify the unknown surfactants present in flowback and produced water from oil and gas wells in the Denver-Julesburg Basin (Niobrara Formation) in Weld County, Colorado, USA. Weld County has been drilled extensively during the last five years for oil and gas between 7,000-8,000 feet below land-surface. Polypropylene glycols (PPGs) and polyethylene glycols carboxylates (PEG-Cs) were found for the first time in these flowback and produced water samples. These ethoxylated surfactants may be used as friction reducers, clay stabilizers, and surfactants. Ultrahigh-performance liquid chromatography/quadrupole-time-of-flight mass spectrometry (UHPLC/QTOF-MS) was used to separate and identify the different classes of PPGs, PEG-Cs, and their isomers. The Kendrick mass scale was applied along with mass spectrometry/mass spectrometry (MSMS) with accurate mass for rapid and unequivocal identification. The PPGs and their isomers occur at the ppm concentration range and may be useful as "fingerprints" of hydraulic-fracturing. Comparing these detections to the compounds used in the fracturing process from FracFocus 3.0 (https://fracfocus.org), it appears that both PPGs and polyethylene glycols (PEGs) are commonly named as additives, but the PEG-Cs have not been reported. The PEG-Cs may be trace impurities or degradation products of PEGs.

*Corresponding Author: michael.thurman@colorado.edu, Emails: $\underline{\text { imma.ferrer@colorado.edu, }}$ james.rosenblum@colorado.edu, karl.linden@colorado.edu, joseph.ryan@ colorado.edu
\end{abstract}

Keywords: Hydraulic fracturing, polypropylene glycols, accurate mass, LC/QTOF-MS 


\subsection{Introduction}

Hydraulic fracturing is the process that aids in the removal of oil and gas from petroleum rich geologic formations by injecting proppants (sand), and a mixture of chemicals that consist of surfactants, clay stabilizers, biocides, friction reducers, and other substances meant to aid in the removal of trapped oil and gas [1-2]. Along with hydraulic fracturing is the process of horizontal drilling that creates long flow paths through the oil- and gas-bearing formations. This combination of hydraulic fracturing and horizontal drilling has created a revolution in removing oil and gas from impervious rock formations that were previously uneconomical [3]. However, there are environmental concerns for surface and groundwater quality [3-5], as well as air quality [6]. For example, the Environmental Protection Agency has recently released an assessment of the scientific literature on hydraulic fracturing to identify factors that affect drinking water quality [7]. The scope of the report [7] deals with five main activities: water acquisition, chemical mixing, well injection, flowback and produced water, and wastewater treatment and disposal.

The initial water containing the engineered fluids that returns during the hydraulic fracturing of the well is called "flowback water". This water is separated from the "produced water", which returns later after the fracturing process is complete and during oil and gas recovery [2]. The produced water is separated by an oil and gas separator on site. The formation is "producing" oil, gas, and water at this time. The gas is stripped and piped away; the oil and water are separated and go to different tanks for later recovery, processing, and disposal. Thus, the produced water may be a combination of the original hydraulic fracturing chemistry and 
water "produced" from the geologic formation. The produced water may be disposed both to surface locations and to deep wells, although in the study area of Colorado reported here, the majority of flowback and produced water is disposed into deep wells.

There have been several recent studies and reviews that look at the nature of produced water and the chemicals used in hydraulic fracturing [2, 8-10]. The major focus of these papers has dealt with the hydrocarbons present $[2,8]$ and less on the organic additives used in hydraulic fracturing $[1,11]$. Previous studies have focused on three techniques to analyze the flowback and produced water from hydraulic fracturing: gas chromatography/mass spectrometry (GC/MS) for volatile organic compounds, liquid chromatography/mass spectrometry (LC/MS) for semivolatile and nonvolatile organic compounds, and inductively coupled plasma/mass spectrometry (ICP/MS) for inorganic compounds [11]. These three techniques are being used to characterize the produced water so that both toxicity and remediation may be evaluated for these chemicals $[5,7,12]$. Two major components of the nonvolatile fraction of produced water were recently identified as polyethylene glycols (PEGs) and linear alkylethoxylates (LAEs) by liquid chromatography/quadrupole-time-of-flight-mass spectrometry (LC/QTOF-MS) [13]. These compounds accounted for approximately $20 \%$ of the dissolved organic compounds in flowback and produced waters from eight different wells in the Denver-Julesburg Basin [13]. The principal uses of these glycols are as surfactants, clay stabilizers, and friction reducers [11]. The continued screening of produced water from hydraulically-fractured wells using LC/QTOF-MS has shown that other ethoxylated compounds were present based on regular spacing of mass units differing by either 44 or 58 mass units [14].

Thus, the purpose of this study was to separate and to identity several classes of polymeric surfactants by liquid chromatography/quadrupole-time-of-flight mass spectrometry 
(LC/QTOF-MS), which have not been reported in produced water samples in order to guide research on toxicity, remediation, and treatment. Furthermore, the occurrence of these compounds was compared to data from FracFocus [15] and well disclosures from the State of Colorado, in order to determine if they matched the identifications found by LC/QTOF-MS analysis.

\subsection{Experimental Methods}

2.1.1 Chemicals and reagents. All chemicals used in the study were reagent grade with purity > 98-99\%. Polyethylene glycol and polypropylene glycol were purchased from Sigma-Aldrich (St. Louis, MO). Stock solutions were prepared in methanol.

2.1.2 Sample Collection. The hydraulic fracturing flowback and produced waters investigated were collected from four different wells located in the Wattenberg field (Weld County, CO). Samples JR-4 (produced water at 100 days), JR-5 (produced water at 100 days), and JR-8 (produced water at 100 days) were collected from holding tanks onsite. These samples were then placed on ice, and stored at $4{ }^{\circ} \mathrm{C}$ prior to analysis. Samples JR-4 and -8 were vertical fractured wells greater than two years old, while JR-5 was a horizontal well flowed back 30 days prior to sample collection. Sample JR-0 was from a horizontally fractured well, and was captured within 24 hours of flowback from onsite frack tanks without oil/water separation. All four JR samples were collected in burned glass bottles, filtered through PTFE filters 0.2 micron, and stored at $4^{\circ} \mathrm{C}$ prior to analysis.

2.1.3 Method for Accurate Mass. For accurate mass analysis of the products formed by the studied processes, a liquid chromatography time-of-flight mass spectrometer (LC/TOF-MS) was used. The separation of the analytes was carried out using an HPLC system (vacuum degasser, 
thermostated autosampler, column compartment and a binary pump; Agilent Series 1290, Agilent Technologies, Santa Clara, CA, USA) equipped with a reversed phase $\mathrm{C}_{8}$ analytical column of $150 \mathrm{~mm}$ x $4.6 \mathrm{~mm}$ and $3.5 \mu \mathrm{m}$ particle size (Zorbax Eclipse XDB-C8). Column temperature was maintained at $25^{\circ} \mathrm{C}$. The injected sample volume was $10 \mu \mathrm{L}$. Mobile phases A and B were water with $0.1 \%$ formic acid and acetonitrile and, respectively. The optimized chromatographic method held the initial mobile phase composition (10\% A) constant for 5 min, followed by a linear gradient to $100 \% \mathrm{~A}$ after $30 \mathrm{~min}$. The flow rate was $0.6 \mathrm{~mL} / \mathrm{min}$. A 10 -min post-run time was used after each analysis. This HPLC system was connected to an ultra-highdefinition quadrupole time-of-flight mass spectrometer Model 6540 Agilent (Agilent Technologies, Santa Clara, CA, USA) equipped with electrospray Jet Stream Technology, operating in positive ion mode, using the following operation parameters: capillary voltage: 3500 $\mathrm{V}$; nebulizer pressure: 45 psig; drying gas: $10 \mathrm{~L} / \mathrm{min}$; gas temperature: $250^{\circ} \mathrm{C}$; sheath gas flow: $11 \mathrm{~L} / \mathrm{min}$; sheath gas temperature: $350{ }^{\circ} \mathrm{C}$; nozzle voltage: $0 \mathrm{~V}$, fragmentor voltage: $190 \mathrm{~V}$; skimmer voltage: $65 \mathrm{~V}$; octopole RF: $750 \mathrm{~V}$. LC/MS-accurate mass spectra were recorded across the range $50-1000 \mathrm{~m} / \mathrm{z}$ at $2 \mathrm{GHz}$. The data recorded was processed with MassHunter software. Accurate mass measurements of each peak from the extracted ion chromatograms were obtained by means of a calibrant solution delivered by an external quaternary pump. This solution contains the internal reference masses (purine $\left(\mathrm{C}_{5} \mathrm{H}_{4} \mathrm{~N}_{4}\right.$ at $\mathrm{m} / z, 121.0509$ and HP-921 [hexakis- $\left(1 \mathrm{H}, 1 \mathrm{H}, 3 \mathrm{H}\right.$-tetrafluoro-pentoxy)phosphazene] $\left(\mathrm{C}_{18} \mathrm{H}_{18} \mathrm{O}_{6} \mathrm{~N}_{3} \mathrm{P}_{3} \mathrm{~F}_{24}\right)$ at $\mathrm{m} / z$. 922.0098. The instrument provides a mass resolving power of $30,000 \pm 500(\mathrm{~m} / \mathrm{z}, 1522)$. Stability of mass accuracy was checked daily and if the values went above 2 ppm error then the instrument was recalibrated. The instrument was operated in full-spectrum mode, except in those cases where MSMS was necessary to elucidate chemical structures and for identification of selected compounds 
and degradation products as explained in the results. The isolation width was set at medium $(\sim 4$ $\mathrm{m} / \mathrm{z}$ ) and collision energies of 10, 20, and $40 \mathrm{eV}$ were used for MS-MS experiments. The concentration of PEGs and PPGs were calculated from the 1-ppm standard. The calculations were based upon the total response factor of all isomers. A standard was not available for the PEG-carboxylates; therefore, concentrations were estimated on the response factor of PEGs.

\subsection{Results and Discussion}

3.1.1 Identification of Polyethylene Glycols (PEGs). Figure 1 shows the chromatogram and mass spectrum from a produced water sample from the Wattenburg Field named JR-5. This sample shows a series of peaks separated by 44.0262 mass units between retention times of 5 and 12 minutes and another series of peaks separated by 58.0419 mass units between 13 and 18 minutes. The first mass separation of 44.0262 mass units is equal to the mass of the ethylene oxide group, [- $\left.-\mathrm{CH}_{2} \mathrm{CH}-\mathrm{O}-\right]$. The second mass separation of 58.0419 mass units is equal to the mass of the propylene oxide group, $\left[-\mathrm{CH}_{2} \mathrm{CH}\left(\mathrm{CH}_{3}\right)-\mathrm{O}-\right]$. The Kendrick mass scale was applied to both of these series as shown in Table 1. In 1968, Kendrick published a mass scale [16] based on $\mathrm{CH}_{2}$ equaling exactly 14.0000 , which is also its nominal mass, 14 . The Kendrick mass scaling factor is calculated from the ratio of nominal mass of the group divided by the true accurate mass (see the value 0.999404559 in Table 1 for PEGs). This ratio is then multiplied times the measured mass to calculate the Kendrick mass [16]. The importance of the Kendrick mass is that each peak with the same Kendrick mass defect is related by exactly one ethylene oxide unit to the one before or after it in the chromatogram. See Table 1 which shows the Kendrick mass defect. Thus, it is only necessary to identify the structure of one of the peaks in 
the chromatogram to then know the identity of the remaining compounds with the same Kendrick mass defect.

This calculation was applied to the peaks in the chromatogram of Figure 1, and the results are shown in Table 1 for the putative PEGs from an ethylene oxide with four monomers to 10 monomers (EO-4 to EO-10). For example, the measured mass of $m / z 195.1228$ is converted to $m / z 195.007$ when multiplied by the Kendrick mass converter of 0.999404559 (Table 1). The Kendrick mass defect is consistent with three significant figures at the value of 0.007 , which occurs for each of the proton adducts of the PEGs from EO-4 to EO-10. Table 1 shows seven retention times from 4.3 to 11.1 minutes that correspond to the putative formulas for PEG-EO4 to PEG-EO10 with mass accuracies of $\sim 1 \mathrm{ppm}$. The results in Table 1 for the PEG surfactants match previously reported water samples from hydraulic fracturing [16] and also match a PEG standard for retention times and accurate masses. The concentration of PEGs varied by PEG type and the concentrations are semi-quantitative since the PEG standard is a mixture rather than individual compounds. Generally speaking, the PEG concentrations were in the part per million range as a total of all polymeric species. It would require individual standards for a more exact value, which are not commericially available. All four samples, JR-0, JR-4, JR-5, and JR-8 contained $\sim 1$ ppm concentration of the PEG surfactants as a total of all isomers.

3.1.2 Identification of Polypropylene Glycols (PPGs). A similar calculation is carried out for the putative propylene glycol (PPG) series by multiplying by the Kendrick mass scaling factor of propylene oxide of 0.999278714 (Table 1). The measured mass of one of the suspect PPGs (PPG-PO2) is $m / z 157.0835$ in Table 1 , which was converted to $m / z, 156.970$ and the Kendrick mass defect is 0.970 . It is necessary to correctly identify one of the putative PPG polymers by MS-MS to know that all of the peaks with this same mass defect have been correctly identified 
as a series of PPGs, which is the same procedure used for the PEG identification. Because MSMS analysis does not typically work on the sodium adduct [17], either the proton or ammonium adduct is fragmented. Figure 2 shows the MS-MS of a PPG-PO6 (6 monomers of polypropylene oxide or PO) standard at a nominal mass of $\mathrm{m} / \mathrm{z} 367$ and a retention time of 15.3 minutes compared to the MS-MS spectrum of a peak corresponding to the PPG-PO6 in the JR-5 sample. The match is identical and shows the fragmentation of the PPG-PO6 standard as a loss of 18 mass units (a loss of water) to $\mathrm{m} / \mathrm{z} 349.2583$, and then a series of 58 mass unit losses as the PPG polymer "unzips", so to speak. The peak corresponding to PPG-PO6 in the JR-5 sample first lost the 58 mass unit component $(\mathrm{m} / \mathrm{z}$ 309.2268), then water $(\mathrm{m} / \mathrm{z} 291.2175)$, and then continuous losses of 58 mass units (Figure 2 bottom panel). The result is a mass spectrum with strong intensity ions at $\mathrm{m} / \mathrm{z} 59.0495,117.0909,175.1325$, and 233.1746. These four ions are present in the MS-MS spectra of other PPGs (e.g., PPGs-PO5, -PO7, and -PO9). The pathway of fragmentation for PPG-PO7 is shown in Figures S1 and S2, which gives a slightly more clean and more interpretable spectrum from the MS-MS of the ammonium adduct rather than the proton adduct of the PPG. This result comes from the fact that the loss of ammonia gives a slightly more stable $\mathrm{MH}^{+}$ion for MS-MS fragmentation than the original proton adduct, which may be due to the location of the proton in the coiled PPG structure.

Figure S3 shows the peak intensities for the sodium and ammonium adducts of PPG-PO6, -PO7, and -PO8 and PEGs-PO6, -PO7, -PO8, and -PO9. The sodium adduct of either PPG or PEG is greater in ion intensity when the chain length is short, i.e. less than PPG-PO6 or PEGEO7. The ammonium adduct intensity was equal to that of sodium at PPG-PO7 and greater than that of sodium at PPG-PO8, which is one monomer unit shorter than the PEG polymer, where equality of ion intensities of the sodium and ammonium adducts occurred for PEG-EO8 and the 
ammonium adduct was greater at PEG-EO9 than the sodium adduct (Figure S3). This difference may be attributable to the slightly more hydrophobic nature of the PPG, which is indicated by its longer retention time on the $\mathrm{C}_{8}$ column for the same chain length of monomers, i.e. ethylene oxide or propylene oxide. Previous work [13] shows that the ion intensities for the sodium and ammonium adducts of the PEGs were approximately equal or greater at a chain length of PEGEO8. However, at PEG-EO9, the ion intensity of the ammonium adduct was greater than that of the sodium adduct. This change in ion intensity was attributed to the more favorable structure of the gaseous PEG ion surrounding either the ammonium ion in a "ball-like" structure [13]. All four of the samples, JR-0, JR-4, JR-5, and JR-8 contained 1 ppm concentration of the PPG surfactants as a total of all isomers.

\subsubsection{Identification of Polyethylene Glycol Carboxylates (PEG-C). Figure 1 shows small} chromatographic peaks at 9.8 to 10.5 minutes, which varied by 44.0262 mass units, similar to what was observed for the PEGs. The mass of the peak at 9.8 minutes was $m / z$ 363.1626 (Figure 3). This mass also had companion adducts at $\mathrm{m} / \mathrm{z} 341.1810$ and 358.2076 , which indicates the formation of both the proton adduct $(\mathrm{m} / \mathrm{z} 341.1810)$ and the ammonium adduct $(\mathrm{m} / \mathrm{z} 358.2076)$. Thus, the mass at $m / z 363.1626$ is the sodium adduct because it was 21.9816 mass units larger than its proton adduct at $m / z 341.1810$.

Figure 3 also shows that there is a mass at $\mathrm{m} / \mathrm{z} 385.1449$ that is 21.9823 mass units larger than the sodium adduct (this addition consists of sodium ion minus a proton), which indicates that the compound at 9.8 minutes contains two sodium adducts. The accurate mass confirms this structure as $\mathrm{C}_{14} \mathrm{H}_{28} \mathrm{O}_{9} \mathrm{Na}_{2}$, with a calculated exact mass of $m / z$ 385.1451, which is within 1 ppm of the measured mass of 385.1449. The double sodium adduct indicates the presence of a carboxyl group that is present as the sodium salt [13]. All of PEG-Cs have this second sodium 
adduct present. Figure 4 shows the MS-MS spectrum of the peak at 10.4 min corresponding to the putative PEG-C-EO7. There is an initial loss of ammonia from the $m / z \quad 402$ to yield the $\mathrm{MH}^{+}$ at $m / z$ 385.2065, followed by two pathways. One is the loss of 46.0048 mass units, which corresponds to the loss of the carboxyl group as formic acid, to give the $m / z 339.2017$ ion. The other pathway is the loss of water directly from the $\mathrm{MH}^{+}$to give the $m / z 367.1954$ ion. After the loss of water, the ion continues to fragment with losses of 44 mass units to give major ions at $\mathrm{m} / \mathrm{z}$ 279.1440, 235.1177, and 103.0389, where 103.0389 is the major diagnostic ion. The major ions of the PEG structure of $m / z 89.0957,133.0856$, and 177.1118 arise from the $\mathrm{m} / \mathrm{z} 339.2017$ ion [13], which subsequently loses methanol (30 mass units) and a series of 44 mass losses constituting a continuous loss of 44 mass units to give the major ions of the PEG structure. We were not able to obtain a standard of the putative PEG-C-EO7; thus, the structure remains unconfirmed. Based on the response factor of the PEGs, the PEG-Cs are approximately 10-20 times less concentrated, which places them in the 50 to $100 \mathrm{ppb}$ concentration range for all four samples.

Similar to the PEGs, the putative PEG-Cs show the switch from a sodium adduct to an ammonium adduct as the major ion in the mass spectrum at PEG-C-EO8 (Figure S4). Thus, the number of monomer units in the PEG-C is equal to the PEG monomers when adduct formation shifts from sodium to ammonium as the major ion in the mass spectrum (Figure S4).

Although the origin of the PEG-Cs is not known, they are probably not added purposefully in the hydraulic fracturing fluid since. This speculation is based on several facts. First they are not mentioned in FracFocus as additives; secondly, they are present at low concentrations relative to the PEGs and PPGs in the flowback samples; and lastly, they are known as biological degradates of PEGs. Therefore, it is likely that they are either minor 
impurities in the PEGs or that some biological or thermal degradation has occurred to give rise to the carboxylate structure. More evidence and data are needed to sort out these possibilities. Several authors have suggested that downhole reactions may occur [2] and this topic is an important one for future research. However, we have analyzed two commercially available surfactant mixtures that contain PEGs. Both mixtures contained trace levels of the PEG carboxylates, which suggests that they are trace components rather than downhole degradates. This work was done after a reviewer's comment to check commercial mixtures.

3.1.4 Chromatography of PEGs and PPGs. PEG is polymerized by free radical reaction with an initiator of ethylene glycol and propagating molecules of ethylene oxide [14]. With PEGs, there can be only one isomer for each PEG because the monomer is symmetrical on either end of the molecule, which creates an homopolymer; therefore, it does not matter which end of the molecule forms the free radical and attacks the next monomer and so forth. At the end of polymerization, the polymer formed has only one isomer. This is shown in the chromatography of the PEGs in Figure 1 with sharp 10-second Gaussian-shaped peaks and no tailing. Likewise, the putative PEG-C-EO series will also have only one isomer, and they too show narrow 10second peaks with a Gaussian-shape (Figure 1).

In a similar fashion to PEGs, PPGs are polymerized by free radical reaction with an initiator of propylene glycol and propagating molecules of propylene oxide [18]. However, the polymerization process is different for PPGs. The oxygen on each end of the monomer is different; thus, the free radical polymerization will form a suite of isomers that increases with the number of monomeric units. In theory, PPG-PO2 will have three possible isomers, and PPGPO3 should have 7 isomers (Figure S5). The formation of isomers that are possible will approximately double with each new PPG monomer addition. 
We examined the chromatograms for this isomer progression in the PPG standard and sample JR-5 by extracting the accurate masses for PPG-PO2 and PPG-PO3 (see Figure S5). PPG-PO2 contains three isomers in both the standard and the sample with the accurate mass of $\mathrm{m} / z$ 157.0835. PPG-PO3 contains 5 isomers in the standard and 13 isomers in the sample with the accurate mass of $m / z$ 215.1254. The standard shows slightly less isomers than is possible, while the sample shows nearly double the amount of isomers expected. The standard was most likely synthesized with high-grade reagents, which leads to the theoretical number of isomers, or less (because of lack of sensitivity of detection rather than formation). Whereas the PPG used in the hydraulic fracturing mixture may have contained non-reagent grade chemicals with trace levels of another propagator, such as 1-propanol, which would give the larger number of isomers found in the JR-5 sample while maintaining the correct accurate mass. If this was the case that 1-propanol was present, then the number of possible PPG-PO2 isomers increases to six, and the number of possible trimers increases to 18 . This explanation would explain the extra number of isomers found in sample JR-5, while maintaining the correct accurate mass for each PPG isomer, because any other trace ingredient would give an incorrect accurate mass. We analyzed three other samples (JR-0, -4, and -8) from different wells, all of which contained PPGs. The PPGPO2 and PPG-PO3 polymers had from 3 to 13 isomers with varying intensities depending on which of the three samples were tested, which suggests that isomers of PPG-PO3 could be useful as a "fingerprint" of different hydraulic fracturing fluids. At longer PPG chain lengths it is not possible to separate the isomers as they increase geometrically with each monomer added.

Figure S6 shows the entire extracted chromatogram for the PPG series from PPG-PO3 to PPG-PO12. The large number of possible isomers are more than can be separated by UHPLC, which leads to the chromatography of each PPG varying to greater than 2 minutes, while each 
individual isomer is only a 10 second peak (Figure S6). Furthermore, the shape of the PPG peaks are not Gaussian but somewhat concave on the front and back, which would indicate that there is an exponential increase in the number of isomers as each monomer is added to the PPG polymer. The PPG-PO12 shows a bimodal distribution at 21.5 and 22.3 min, which is another possible "fingerprint" for each of the four wells that were sampled. Thus, the PPGs may make useful markers, or "fingerprints", of produced water from hydraulically-fractured wells or groundwater contaminated by fracking fluids. Finally, databases have been built for each of the two surfactant families, similar to our previous work on PEGs and LAEs (13), and are available if requested.

3.1.5 Toxicity Considerations. Both PEGs and PPGs are common products used in medicines and foods. PEGs are used in medications as a coating and as a prescription laxative. PPGs are commonly used in food, such as ice cream and frozen desserts. PPGs are also added as a carrier of nicotine in e-cigarettes, suggesting that they are considered non-toxic. Less is known about the PEG-Cs, but presumably they are similar to PEGs in toxicity and mode of action. Many states require that ingredients used in hydraulic fracturing are reported to FracFocus [15]. For example, the use of PEGs appears in 6500 records based on our computer search of FracFocus and PPG appears in 540 cases with some incorrect spellings, but the correct CAS numbers.

It is important to distinguish between the monomers and polymers when discussing toxicity issues, since they are quite different. For example, the human toxicity of ethylene glycol is considerable, while propylene glycol is of much less toxicity [19]. This was demonstrated experimentally by Kassotis et al. [19] who found ethylene glycol to have anti-estrogenic activity, while Ghirardini et al. [20] found PEGs and PEG-Cs to be none toxic at their highest concentration tested of $200 \mathrm{mg} / \mathrm{L}$ (EC50 assay). A final question raised by our research is, what 
is the relative abundance of the monomer compared to polymers in hydraulic fracturing flowback and produced waters? This is our next area of study, which deals with the amount of monomers present and whether there can be degradation of either PEG or PPG to form the monomers, which have a higher toxicity.

\subsection{References}

[1] I. Ferrer, E.M. Thurman, Analysis of hydraulic fracturing additives by LC-Q-TOF-MS. Anal. Bioanal. Chem. 407 (2015) 6417-6428.

[2] S.J. Maguire-Boyle, A.R. Barron, Organic compounds in produced waters from shale gas wells, Environ. Sci. Processes Impacts. 16 (2014) 2237.

[3] R.D. Vidic, S.I. Brantley, J.M. Vandenborsche, D. Yoxtheimer, J.D. Abad, Impact of shale gas development on regional water quality, Sci. 340 (2013) 6134.

[4] N.R. Warner, R.B. Jackson, T.H. Darrah, S.G. Osborn, A. Down, K.G. Zhao, A. White, A. Vengosh, Geochemical evidence for the possible migration of Marcellus brine to shallow aquifers in Pennsylvania, Proc. Nat. Academy Sci. 109 (2012) 11961.

[5] B.C. Gordalla, U. Ewers, F.H. Frimmel, Hydraulic fracturing: a toxicological threat for groundwater and drinking-water, Environ. Earth Sci. 70 (2013) 3875.

[6] T.Colborn, K. Schultz, L. Herrick, C. Kwiatkowski, An exploratory study of air quality near natural gas operations, Human Ecolog. Risk Assesment. 20 (2014) 86.

[7] Assessment of the potential impacts of hydraulic fracturing for oil and gas on drinking water resources (external review draft)-EPA/600/R-15/047 (2015). [8] W. Orem, C. Tatu, M. Varonka, H. Lerch, A. Bates, M. Engle, L. Crosby, J. McIntosh, Organic substances in produced and formation water from unconventional natural gas extraction in coal and shale, Int. J. Coal. Geol. 126 (2014) 20-31.

[9] W. T. Stringfellow, J.K. Domen, M.K. Camarillo, W.L. Sandelin, S. Borglin, Physical, chemical, and biological characteristics of compounds used in hydraulic fracturing. J. Hazard. Mater. 275 (2014) 37-54.

[10] A. Vengosh, R.B. Jackson, N. Wagner, T.H. Darrah, A. Kondash, A critical review of the risks to water resources from unconventional shale gas development and hydraulic fracturing in the United States, Environ. Sci. Technol. 48 (2014) 8334-8348.

[11] I. Ferrer, E.M. Thurman, Chemical constituents and analytical approaches for hydraulic fracturing waters, Trends in Environ. Anal. Chem. 5 (2015) 18-25. 
[12] Y. Lester, I. Ferrer, E.M. Thurman, K.A. Sitterley, J.A. Korak, G. Aiken, K.G. Linden, Characterization of hydraulic fracturing flowback water in Colorado: Implications for water treatment, Sci. Total Environ. 512-513 (2015) 637-644.

[13] E.M. Thurman, I. Ferrer, J. Blotevogel, T. Borch, Analysis of hydraulic fracturing flowback and produced water using accurate mass: identification of ethoxylated surfactants, Anal. Chem. 86 (2014) 9653-9661.

[14] E.M. Thurman, I. Ferrer, Accurate mass analysis of wastewater from hydraulic fracturing, Pittsburg Analytical Chemistry Conference, Abstract and oral presentation, Chicago, (2015).

[15] FracFocus 3.0 (https://fracfocus.org)

[16] E. Kendrick, A mass scale based on $\mathrm{CH}_{2}=14.0000$ for high resolution mass spectrometry of organic compounds, Anal. Chem. 35 (1963) 2146-2154.

[17] I. Ferrer, E.M. Thurman, Liquid chromatography Time-of-Flight Mass Spectrometry: Principles, Tools, and Applications for Accurate Mass Analysis: John Wiley and Sons, Inc., New York, 2009, 261p.

[18] E. Andrzejewska, Photopolymerization kinetics of multfunctional monomers: Progress Polymer Sci., 26, (2001) 605-665.

[19] C.D. Kassotis, D.E. Tillitt, J.W. Davis, A.M. Hormann, S.C. Nagel, Estrogen and androgen receptor activities of hydraulic fracturing chemicals and surface and ground water in a drillingdense region. Endocrinology, 155 (2014) 897-907.

[20] A.V. Ghirardini, A.A. Novelli, B. Likar, G. Pojana, P.F. Ghetti, A. Marcomini, (2001). Sperm cell toxicity test using sea urchin Paracentrotus lividus lamarck (Echinodermata: Echinoidea): sensitivity and discriminatory ability toward anionic and nonionic surfactants. Environ. Tox. Chem.20 (2001) 644-651.

\section{Acknowledgments}

"The research was conducted as part of the AirWaterGas Sustainability Research Network (http://airwatergas.org/) funded by the National Science Foundation under Grant No. CBET1240584. Any opinion, findings, and conclusions or recommendations expressed in this article are those of the author(s) and do not necessarily reflect the views of the National Science Foundation." The authors thank Jerry Zweigenbaum and Craig Marvin of Agilent Technologies for support of the LC/QTOF-MS system during this research project. 
Table 1. Kendrick Mass Table for three classes of glycol surfactants found in produced water sample, JR-5. KM scaling factor for PEGs is 0.999404559, for PPGs is 0.999278714, and for PEG-Cs is 0.99940456.

\begin{tabular}{|c|c|c|c|c|c|c|c|}
\hline $\begin{array}{l}\text { Retention } \\
\text { Time }\end{array}$ & $\begin{array}{l}\text { Measured } \\
\text { Mass }\end{array}$ & $\begin{array}{l}\text { Kendrick } \\
\text { Mass }\end{array}$ & $\begin{array}{c}\text { Kendrick } \\
\text { Mass } \\
\text { Defect }\end{array}$ & $\begin{array}{l}\text { Putative } \\
\text { Formula }\end{array}$ & $\begin{array}{c}\text { Putative } \\
\text { Identification }\end{array}$ & $\begin{array}{l}\text { Calculated } \\
\text { Exact } \\
\text { Mass }\end{array}$ & $\begin{array}{c}\text { Measured } \\
\text { Mass } \\
\text { Error }\end{array}$ \\
\hline & & & & $\begin{array}{c}\text { PEG } \\
\text { Surfactants } \\
\text { Proton Adduct }\end{array}$ & & & \\
\hline 4.3 & 195.1228 & 195.007 & 0.007 & C8H18O5 & PEG-EO4 & 195.1227 & $0.5 \mathrm{ppm}$ \\
\hline 5.4 & 239.1489 & 239.007 & 0.007 & $\mathrm{C} 10 \mathrm{H} 22 \mathrm{O} 6$ & PEG-EO5 & 239.1489 & $0.0 \mathrm{ppm}$ \\
\hline 7.3 & 283.1752 & 283.007 & 0.007 & $\mathrm{C} 12 \mathrm{H} 26 \mathrm{O} 7$ & PEG-EO6 & 283.1751 & $0.5 \mathrm{ppm}$ \\
\hline 9.4 & 327.2018 & 327.007 & 0.007 & $\mathrm{C} 14 \mathrm{H} 30 \mathrm{O} 8$ & PEG-EO7 & 327.2013 & $1.8 \mathrm{ppm}$ \\
\hline 10.2 & 371.2284 & 371.007 & 0.007 & C16H34O9 & PEG-EO8 & 371.2276 & $2.5 \mathrm{ppm}$ \\
\hline 10.7 & 415.2542 & 415.007 & 0.007 & $\mathrm{C} 18 \mathrm{H} 38 \mathrm{O} 10$ & PEG-EO9 & 415.2538 & 1.0 ppm \\
\hline \multirow[t]{2}{*}{11.1} & 459.2801 & 459.007 & 0.007 & $\mathrm{C} 20 \mathrm{H} 42 \mathrm{O} 11$ & PEG-EO10 & 459.2800 & $0.2 \mathrm{ppm}$ \\
\hline & & & & $\begin{array}{c}\text { PPG } \\
\text { Surfactants } \\
\text { Sodium } \\
\text { Adduct }\end{array}$ & & & \\
\hline 5.2 & 157.0835 & 156.970 & 0.970 & $\mathrm{C} 6 \mathrm{H} 14 \mathrm{O} 3$ & PPG-PO2 & 157.0841 & $3.8 \mathrm{ppm}$ \\
\hline 10.4 & 215.1254 & 214.970 & 0.970 & $\mathrm{C} 9 \mathrm{H} 20 \mathrm{O} 4$ & PPG-PO3 & 215.1254 & $0.0 \mathrm{ppm}$ \\
\hline 12.6 & 273.1674 & 272.970 & 0.970 & $\mathrm{C} 12 \mathrm{H} 26 \mathrm{O} 5$ & PPG-PO4 & 273.1672 & $0.8 \mathrm{ppm}$ \\
\hline 13.8 & 331.2092 & 330.970 & 0.970 & $\mathrm{C} 15 \mathrm{H} 32 \mathrm{O} 6$ & PPG-PO5 & 331.2092 & $0.3 \mathrm{ppm}$ \\
\hline 15.4 & 389.2510 & 388.970 & 0.970 & C18H38O7 & PPG-PO6 & 389.2510 & $0.0 \mathrm{ppm}$ \\
\hline 16.8 & 447.2932 & 446.971 & 0.971 & $\mathrm{C} 21 \mathrm{H} 44 \mathrm{O} 8$ & PPG-PO7 & 447.2928 & $0.9 \mathrm{ppm}$ \\
\hline 17.8 & 505.3350 & 504.971 & 0.971 & C24H50O9 & PPG-PO8 & 505.3347 & $0.6 \mathrm{ppm}$ \\
\hline 19.0 & 563.3765 & 562.970 & 0.970 & $\mathrm{C} 27 \mathrm{H} 56 \mathrm{O} 10$ & PPG-PO9 & 563.3766 & $0.2 \mathrm{ppm}$ \\
\hline \multirow[t]{2}{*}{20.0} & 621.4182 & 620.970 & 0.970 & C30H62O11 & PPG-PO10 & 621.4184 & $0.3 \mathrm{ppm}$ \\
\hline & & & & $\begin{array}{c}\text { PEG-C } \\
\text { (Carboxylate) } \\
\text { Sodium } \\
\text { Adduct }\end{array}$ & & & \\
\hline 3.5 & 187.0578 & 186.946 & 0.946 & C6H12O5 & PEG-C-EO2 & 187.0577 & $0.5 \mathrm{ppm}$ \\
\hline 4.5 & 231.0841 & 230.947 & 0.947 & C8H16O6 & PEG-C-EO3 & 231.0839 & $1.0 \mathrm{ppm}$ \\
\hline 5.9 & 275.1100 & 274.946 & 0.946 & $\mathrm{C} 10 \mathrm{H} 20 \mathrm{O} 7$ & PEG-C-EO4 & 275.1101 & $0.4 \mathrm{ppm}$ \\
\hline 8 & 319.1364 & 318.946 & 0.946 & $\mathrm{C} 12 \mathrm{H} 24 \mathrm{O} 8$ & PEG-C-EO5 & 239.1363 & $0.4 \mathrm{ppm}$ \\
\hline 9.8 & 363.1625 & 362.946 & 0.946 & $\mathrm{C} 14 \mathrm{H} 28 \mathrm{O} 9$ & PEG-C-EO6 & 363.1626 & $0.1 \mathrm{ppm}$ \\
\hline 10.4 & 407.1889 & 406.946 & 0.946 & $\mathrm{C} 16 \mathrm{H} 32 \mathrm{O} 10$ & PEG-C-EO7 & 407.1888 & $0.3 \mathrm{ppm}$ \\
\hline 10.9 & 451.2153 & 450.947 & 0.947 & $\mathrm{C} 18 \mathrm{H} 36 \mathrm{O} 11$ & PEG-C-EO8 & 451.2150 & $0.7 \mathrm{ppm}$ \\
\hline 11.3 & 495.2417 & 494.947 & 0.947 & $\mathrm{C} 20 \mathrm{H} 40 \mathrm{O} 12$ & PEG-C-EO9 & 495.2412 & $1.0 \mathrm{ppm}$ \\
\hline 11.6 & 539.2680 & 538.947 & 0.947 & $\mathrm{C} 22 \mathrm{H} 44 \mathrm{O} 13$ & PEG-C-EO10 & 539.2674 & $1.1 \mathrm{ppm}$ \\
\hline
\end{tabular}


Table 1. Kendrick Mass Table for three classes of glycol surfactants found in produced water sample, JR-5. KM scaling factor for PEGs is 0.999404559, for PPGs is 0.999278714, and for PEG-Cs is 0.99940456.

\begin{tabular}{|c|c|c|c|c|c|c|c|}
\hline $\begin{array}{l}\text { Retention } \\
\text { Time }\end{array}$ & $\begin{array}{l}\text { Measured } \\
\text { Mass }\end{array}$ & $\begin{array}{l}\text { Kendrick } \\
\text { Mass }\end{array}$ & $\begin{array}{c}\text { Kendrick } \\
\text { Mass } \\
\text { Defect }\end{array}$ & $\begin{array}{l}\text { Putative } \\
\text { Formula }\end{array}$ & $\begin{array}{c}\text { Putative } \\
\text { Identification }\end{array}$ & $\begin{array}{l}\text { Calculated } \\
\text { Exact } \\
\text { Mass }\end{array}$ & $\begin{array}{c}\text { Measured } \\
\text { Mass } \\
\text { Error }\end{array}$ \\
\hline & & & & $\begin{array}{c}\text { PEG } \\
\text { Surfactants } \\
\text { Proton Adduct }\end{array}$ & & & \\
\hline 4.3 & 195.1228 & 195.007 & 0.007 & C8H18O5 & PEG-EO4 & 195.1227 & $0.5 \mathrm{ppm}$ \\
\hline 5.4 & 239.1489 & 239.007 & 0.007 & $\mathrm{C} 10 \mathrm{H} 22 \mathrm{O} 6$ & PEG-EO5 & 239.1489 & 0.0 ppm \\
\hline 7.3 & 283.1752 & 283.007 & 0.007 & $\mathrm{C} 12 \mathrm{H} 26 \mathrm{O} 7$ & PEG-EO6 & 283.1751 & $0.5 \mathrm{ppm}$ \\
\hline 9.4 & 327.2018 & 327.007 & 0.007 & $\mathrm{C} 14 \mathrm{H} 30 \mathrm{O} 8$ & PEG-EO7 & 327.2013 & $1.8 \mathrm{ppm}$ \\
\hline 10.2 & 371.2284 & 371.007 & 0.007 & C16H34O9 & PEG-EO8 & 371.2276 & $2.5 \mathrm{ppm}$ \\
\hline 10.7 & 415.2542 & 415.007 & 0.007 & $\mathrm{C} 18 \mathrm{H} 38 \mathrm{O} 10$ & PEG-EO9 & 415.2538 & $1.0 \mathrm{ppm}$ \\
\hline \multirow[t]{2}{*}{11.1} & 459.2801 & 459.007 & 0.007 & $\mathrm{C} 20 \mathrm{H} 42 \mathrm{O} 11$ & PEG-EO10 & 459.2800 & $0.2 \mathrm{ppm}$ \\
\hline & & & & $\begin{array}{c}\text { PPG } \\
\text { Surfactants } \\
\text { Sodium } \\
\text { Adduct }\end{array}$ & & & \\
\hline 5.2 & 157.0835 & 156.970 & 0.970 & $\mathrm{C} 6 \mathrm{H} 14 \mathrm{O} 3$ & PPG-PO2 & 157.0841 & $3.8 \mathrm{ppm}$ \\
\hline 10.4 & 215.1254 & 214.970 & 0.970 & $\mathrm{C} 9 \mathrm{H} 20 \mathrm{O} 4$ & PPG-PO3 & 215.1254 & $0.0 \mathrm{ppm}$ \\
\hline 12.6 & 273.1674 & 272.970 & 0.970 & $\mathrm{C} 12 \mathrm{H} 26 \mathrm{O} 5$ & PPG-PO4 & 273.1672 & $0.8 \mathrm{ppm}$ \\
\hline 13.8 & 331.2092 & 330.970 & 0.970 & $\mathrm{C} 15 \mathrm{H} 32 \mathrm{O} 6$ & PPG-PO5 & 331.2092 & $0.3 \mathrm{ppm}$ \\
\hline 15.4 & 389.2510 & 388.970 & 0.970 & C18H38O7 & PPG-PO6 & 389.2510 & $0.0 \mathrm{ppm}$ \\
\hline 16.8 & 447.2932 & 446.971 & 0.971 & $\mathrm{C} 21 \mathrm{H} 44 \mathrm{O} 8$ & PPG-PO7 & 447.2928 & $0.9 \mathrm{ppm}$ \\
\hline 17.8 & 505.3350 & 504.971 & 0.971 & C24H50O9 & PPG-PO8 & 505.3347 & $0.6 \mathrm{ppm}$ \\
\hline 19.0 & 563.3765 & 562.970 & 0.970 & $\mathrm{C} 27 \mathrm{H} 56 \mathrm{O} 10$ & PPG-PO9 & 563.3766 & $0.2 \mathrm{ppm}$ \\
\hline \multirow[t]{2}{*}{20.0} & 621.4182 & 620.970 & 0.970 & C30H62O11 & PPG-PO10 & 621.4184 & $0.3 \mathrm{ppm}$ \\
\hline & & & & $\begin{array}{c}\text { PEG-C } \\
\text { (Carboxylate) } \\
\text { Sodium } \\
\text { Adduct }\end{array}$ & & & \\
\hline 3.5 & 187.0578 & 186.946 & 0.946 & C6H12O5 & PEG-C-EO2 & 187.0577 & $0.5 \mathrm{ppm}$ \\
\hline 4.5 & 231.0841 & 230.947 & 0.947 & C8H16O6 & PEG-C-EO3 & 231.0839 & $1.0 \mathrm{ppm}$ \\
\hline 5.9 & 275.1100 & 274.946 & 0.946 & $\mathrm{C} 10 \mathrm{H} 20 \mathrm{O} 7$ & PEG-C-EO4 & 275.1101 & $0.4 \mathrm{ppm}$ \\
\hline 8 & 319.1364 & 318.946 & 0.946 & $\mathrm{C} 12 \mathrm{H} 24 \mathrm{O} 8$ & PEG-C-EO5 & 239.1363 & $0.4 \mathrm{ppm}$ \\
\hline 9.8 & 363.1625 & 362.946 & 0.946 & $\mathrm{C} 14 \mathrm{H} 28 \mathrm{O} 9$ & PEG-C-EO6 & 363.1626 & $0.1 \mathrm{ppm}$ \\
\hline 10.4 & 407.1889 & 406.946 & 0.946 & $\mathrm{C} 16 \mathrm{H} 32 \mathrm{O} 10$ & PEG-C-EO7 & 407.1888 & $0.3 \mathrm{ppm}$ \\
\hline 10.9 & 451.2153 & 450.947 & 0.947 & $\mathrm{C} 18 \mathrm{H} 36 \mathrm{O} 11$ & PEG-C-EO8 & 451.2150 & $0.7 \mathrm{ppm}$ \\
\hline 11.3 & 495.2417 & 494.947 & 0.947 & $\mathrm{C} 20 \mathrm{H} 40 \mathrm{O} 12$ & PEG-C-EO9 & 495.2412 & $1.0 \mathrm{ppm}$ \\
\hline 11.6 & 539.2680 & 538.947 & 0.947 & $\mathrm{C} 22 \mathrm{H} 44 \mathrm{O} 13$ & PEG-C-EO10 & 539.2674 & $1.1 \mathrm{ppm}$ \\
\hline
\end{tabular}




\section{Figure Captions}

Figure 1. Chromatographic separation of a series of compounds found in a produced water sample, JR-5, from Weld County, Colorado, USA.

Figure 2. Comparison MS-MS of PPG-PO6 standard and putative unknown in JR-5 sample. The losses of 58.0419 mass units represents the "unzipping" of PPG standard.

Figure 3. Mass spectrum of putative PEG-C (carboxylate)-EO6 and EO7.

Figure 4. MS-MS of the PEG-C-EO7 (carboxylate) for the ammonium adduct at $m / z 402$. 


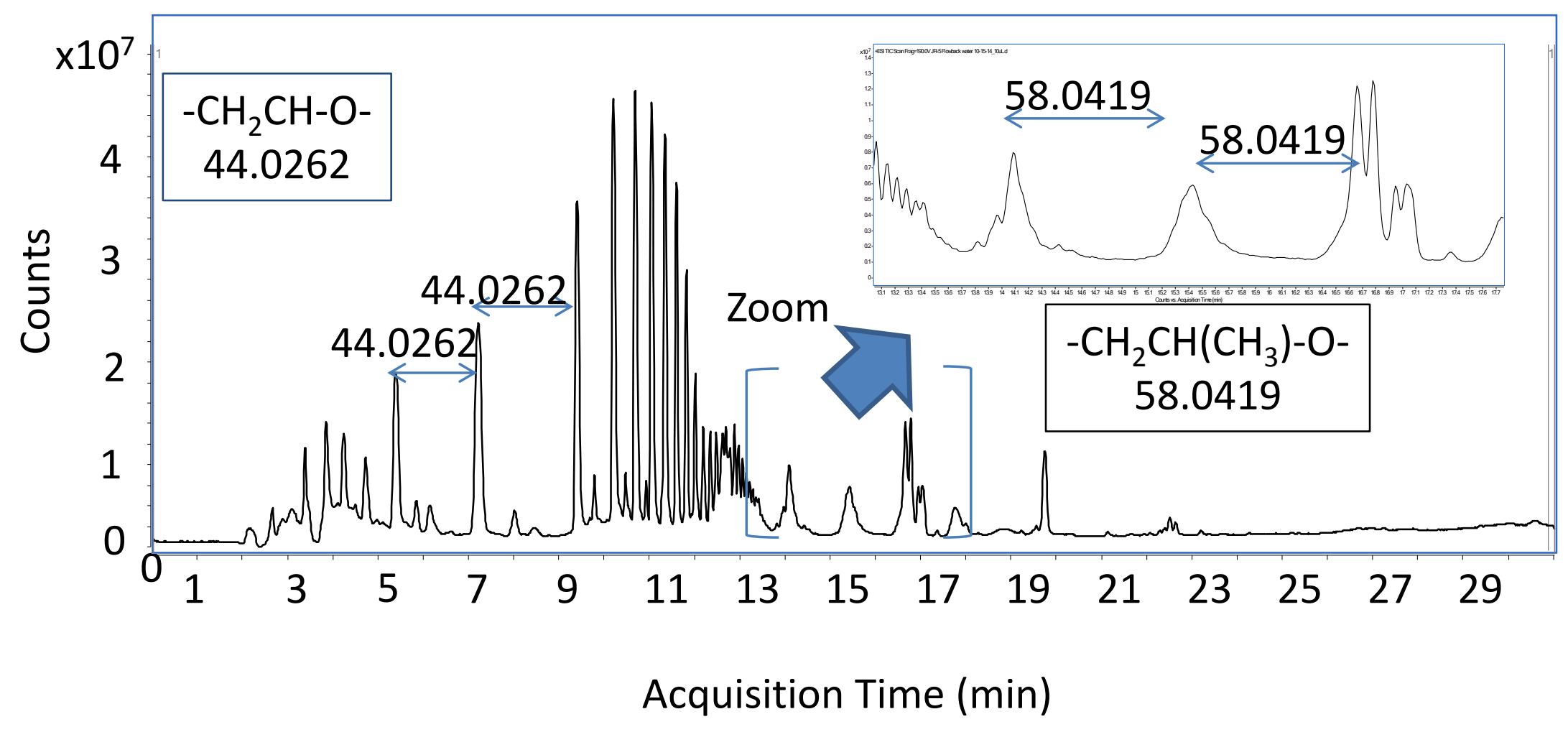

Figure 1 

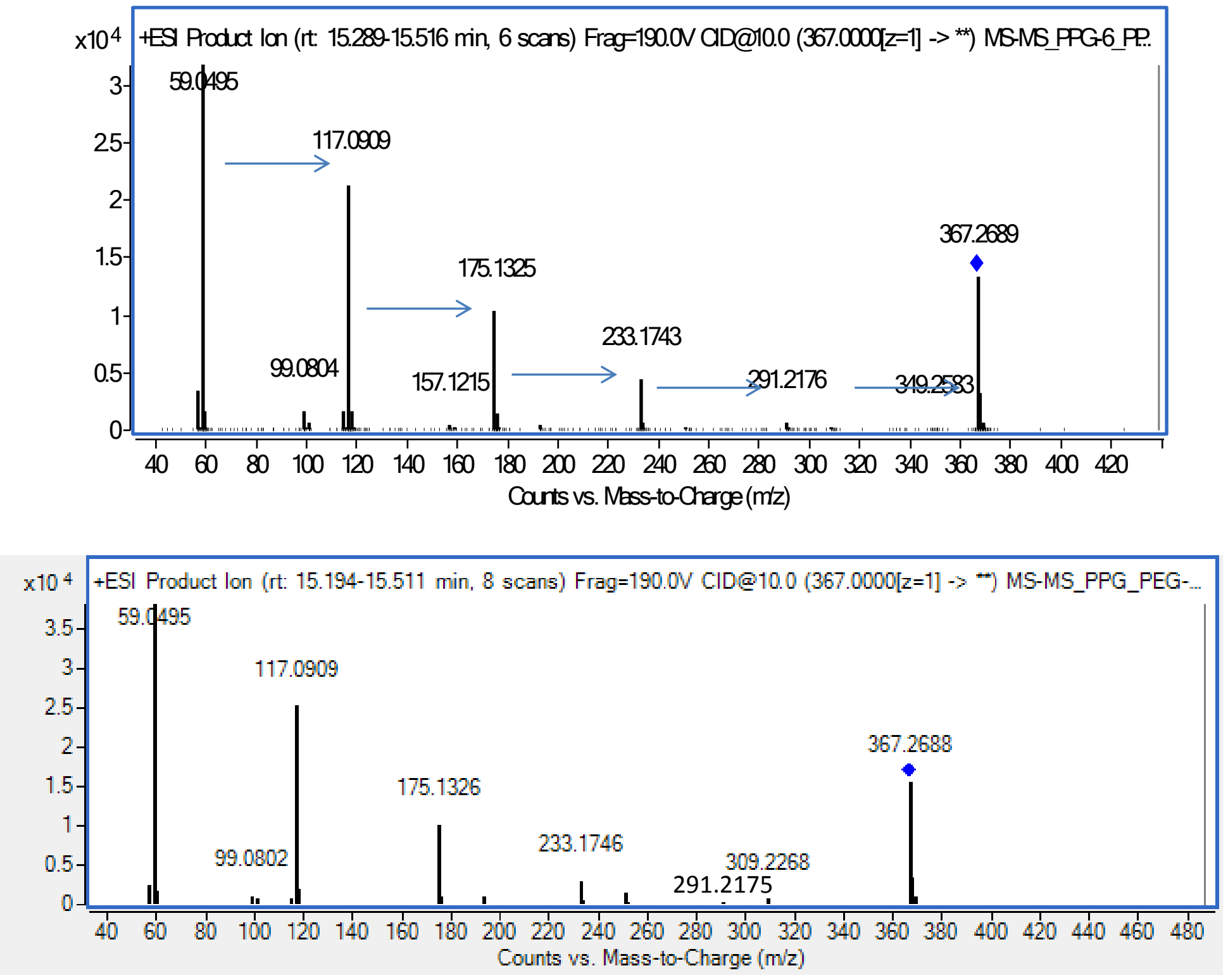

Figure 2. 

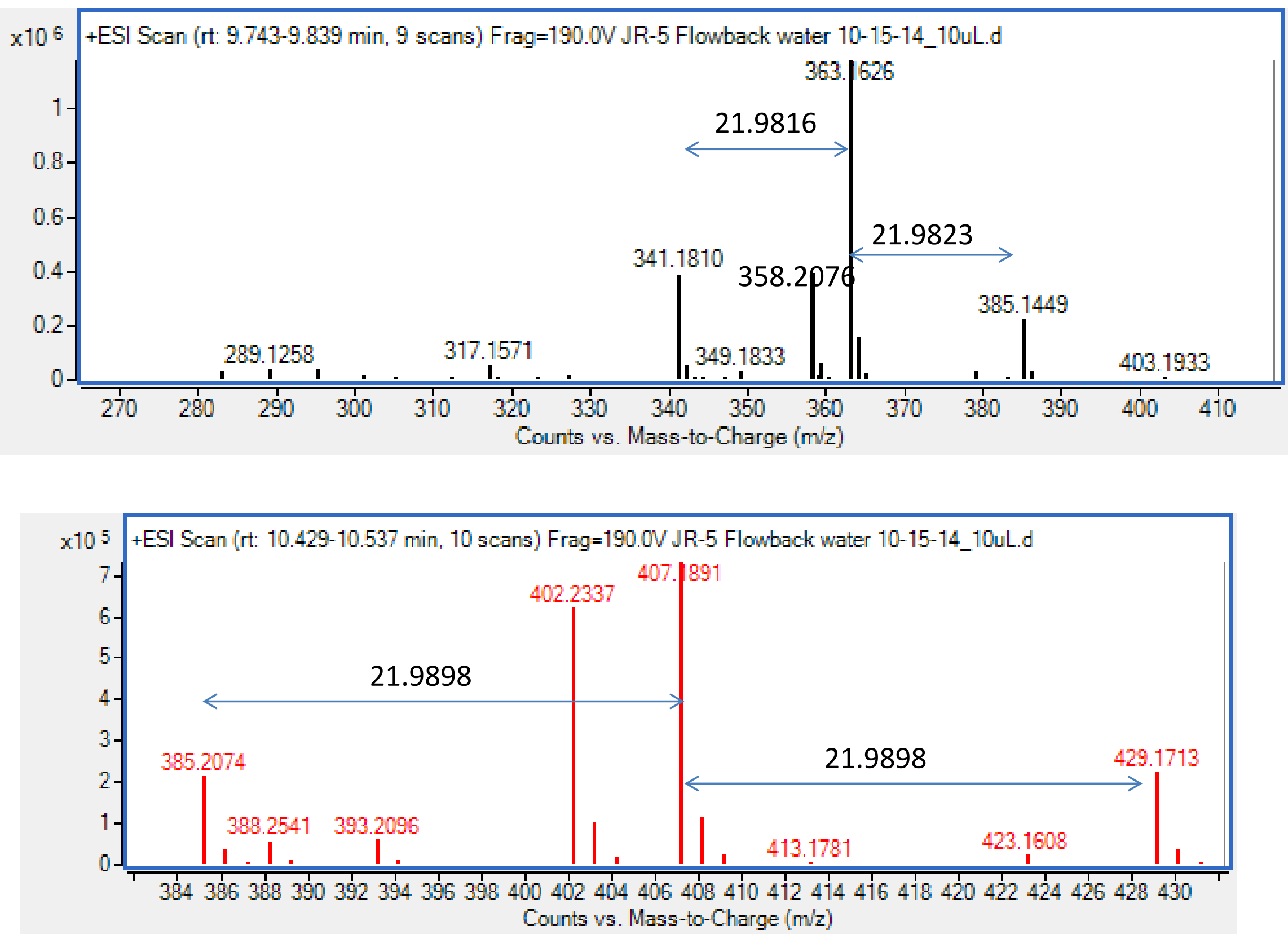

\section{Figure 3.}




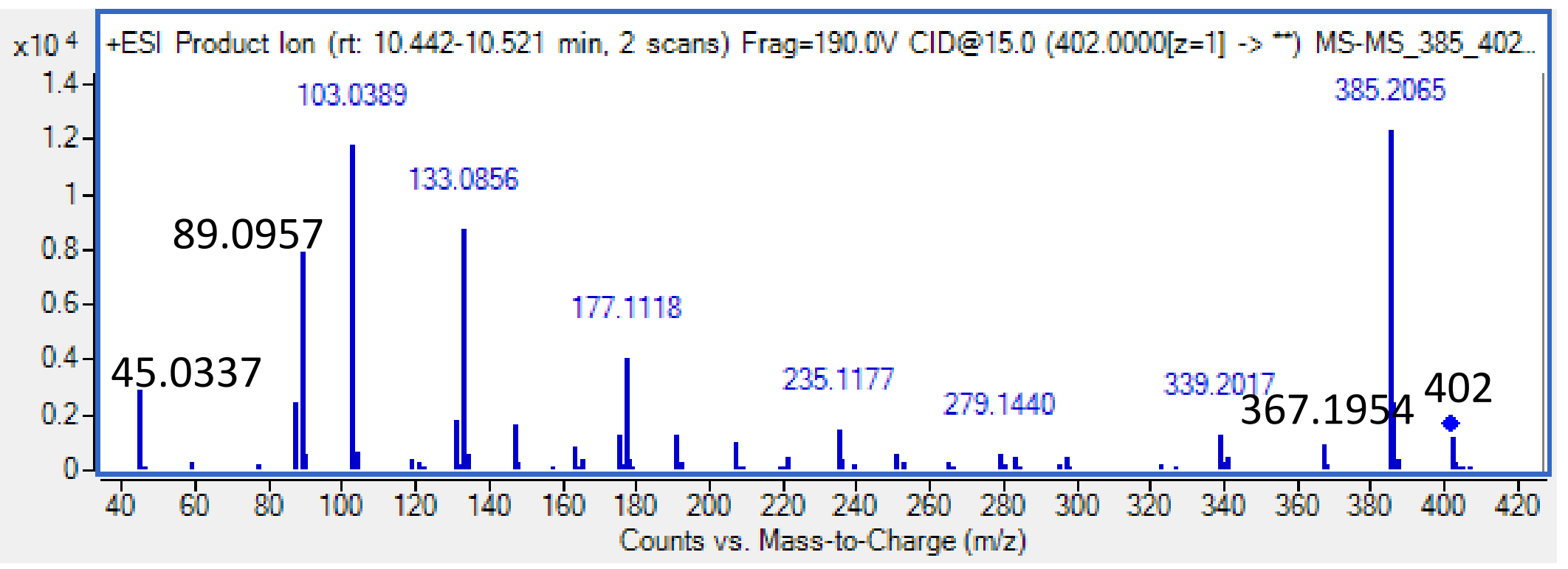

Figure 4. 


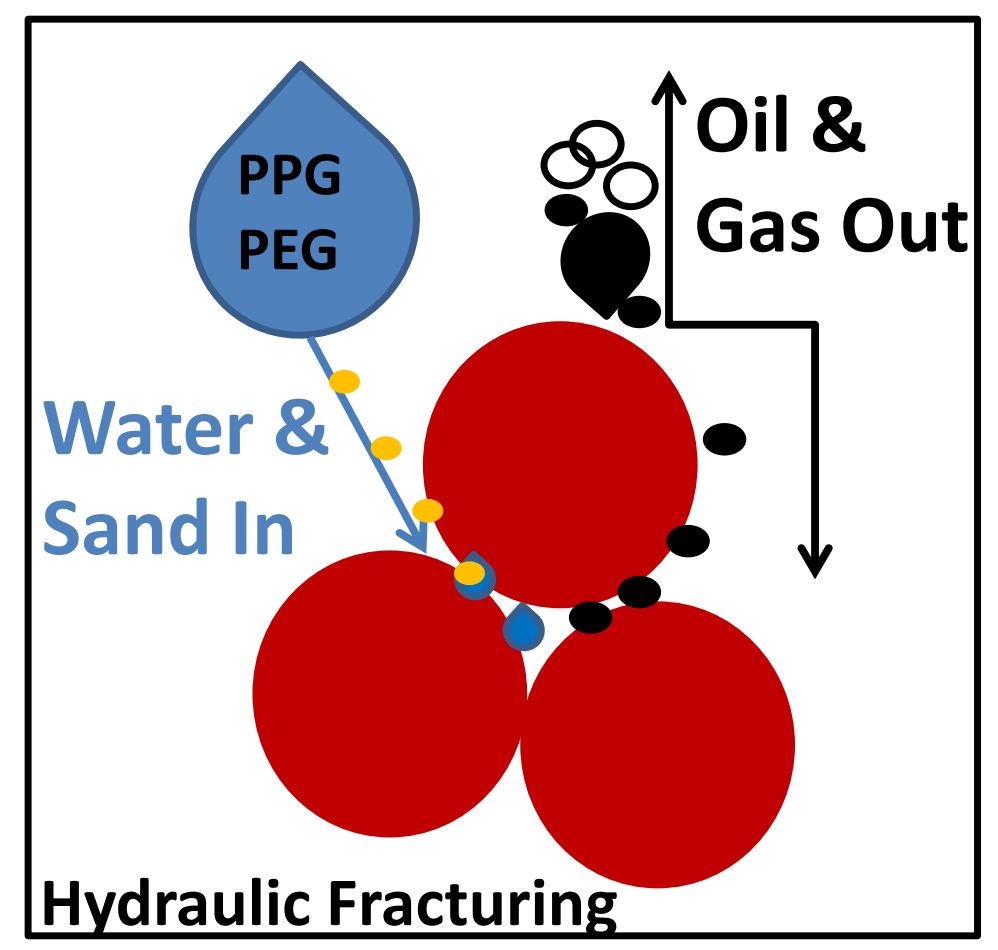

